\title{
AS CONDIÇÕES DAS PENITENCIÁRIAS NO BRASIL E O ESTADO DE COISAS
} INCONSTITUCIONAL

\section{THE CONDITIONS FOR PRISONS IN BRAZIL AND THE THINGS OF STATE UNCONSTITUTIONAL}

\author{
${ }^{1}$ Roberto Correia da Silva Gomes Caldas \\ ${ }^{2}$ Felipe Lascane Neto
}

\section{Resumo}

O artigo objetiva verificar as condições das penitenciárias no Brasil e seu reflexo nos indivíduos encarcerados. Serão objeto de estudo os julgados do Supremo Tribunal Federal relativos ao Recurso Extraordinário (RE) n. 592.581 e à Medida Cautelar na Arguição de Descumprimento de Preceito Fundamental (ADPF) n. 347, em que reconhecido o "estado de coisas inconstitucional" a impor medidas saneadoras pelos Poderes Executivo e Judiciário, com foco nos limites de atuação deste na priorização das políticas públicas de segurança quanto às penitenciárias $\mathrm{e}$ aos direitos fundamentais dos encarcerados à luz do neoconstitucionalismo.

Palavras- chave: Penitenciárias; direitos fundamentais; "estado de coisas inconstitucional"; RE 592.581; APDF 347.

\begin{abstract}
The article aims to verify the conditions of penitentiaries in Brazil and its reflection on prisoners. The Federal Supreme Court judgments in Extraordinary Appeal n. 592.581 (RE) and Precautionary Measure in the Allegation Injunction of breach of fundamental precept n.347 (ADPF), where recognized the "unconstitutional state of affairs" to impose regulatory measures by the Executive Branch and by the Judiciary, focusing on the limits of its performance in the prioritization of public security policies regarding penitentiaries and the fundamental rights of prisoners in the light of neoconstitutionalism.
\end{abstract}

Keywords: Penitentiary; fundamental rights; "unconstitutional state of affairs"; RE 592.581; APDF 347.

\footnotetext{
${ }^{1}$ Mestre e Doutor em Direito do Estado pela Pontifícia Universidade Católica de São Paulo, PUCSP - SP, (Brasil). Professor dos cursos de mestrado e bacharelado em Direito na Universidade Nove de Julho, UNINOVE - SP, (Brasil).E-mail: robertocsgcaldas@uol.com.br

2 Mestrando em Direito pela Universidade nove de Julho, UNINOVE - SP, (Brasil). Procurador do Município de Osasco. E-mail: flascane@uol.com.br
} 


\section{INTRODUÇÃO}

O fenômeno atual da globalização tem alterado a estrutura do Estado, redefinindo sua atuação política, de modo que, ao contrário do que visto em âmbito social e econômico, na área de segurança pública há um incremento significativo de sua ingerência, com novos mecanismos de controle, os quais, todavia, têm sido insuficientes para sua melhora ante a ausência de uma política estatal que não seja apenas governamental e, como tal, sazonal ${ }^{3}$.

E a falta de um planejamento estatal brasileiro duradouro de segurança pública também é consequência da dificuldade que se tem, inclusive, em função da inexistência de transparência e de dados públicos confiáveis sobre a criminalidade e seu perfil ${ }^{4}$.

À luz dessa realidade, o objetivo do presente artigo consubstancia-se em verificar parte de tais questões, qual seja, as condições das penitenciárias no Brasil e a violação aos direitos fundamentais dos encarcerados, a revelar omissão estatal violadora do princípio da dignidade humana dos encarcerados ao não se programar uma política pública de segurança voltada para uma melhora sistêmica prisional, autorizando-se, o reconhecimento do que a doutrina e jurisprudência denominam "estado de coisas inconstitucional"5.

No Brasil, com o julgamento da Medida Cautelar na Ação de Descumprimento de Preceito Fundamental (ADPF) n. 347, o Supremo Tribunal Federal (STF) passou a expressamente acolher a teoria do "estado de coisas inconstitucional" para dispor sobre quais medidas devem ser adotadas pelos Poderes Executivo, Legislativo e Judiciário visando a alterar a realidade de inconstitucionalidade que hoje se apercebe no sistema prisional ${ }^{6}$.

\footnotetext{
${ }^{3}$ Chama atenção a solução de continuidade de projetos nesta área quando da troca de governos, como, v. g., o Programa Nacional de Segurança Pública com Cidadania (Pronasci), criado na gestão Lula, mantido nos primeiros anos de Rousseff e, depois, por ela extinto na segunda parte de seu mandato em substituição pelo projeto Brasil Mais Seguro.

${ }^{4}$ Ao contrário de outros países que possuem anuários por décadas e décadas compilando dados estatísticos, o país apenas verifica alguns projetos específicos, como o anuário do Fórum Brasileiro de Segurança Pública ou Mapa da Violência, sem, todavia, o necessário cunho público.

${ }^{5} \mathrm{Com}$ isso, o controle jurisdicional das políticas públicas, quando violadas normas constitucionais relacionadas a direitos fundamentais, ganhou respaldo no Supremo Tribunal Federal, sob certos limites que serão analisados diante da ausência manifesta de atuação do Poder Público.

${ }^{6}$ As penitenciárias, cadeias de distritos policiais e demais locais para recolhimento de pessoas estão abarrotados. A frase escrita no portão do inferno de Alighieri $(2003,31)$ retrata com crueza o que ora vivencia-se no país em matéria de tratamento prisional: "Abandonai toda a esperança, vós que entrais". Os dados colhidos do Conselho Nacional de Justiça (2014, p. 17), em levantamento realizado em maio de 2014, demonstram a falta de vagas com a qual o sistema penitenciário convive. Para uma população carcerária de 567.655 (quinhentos e sessenta e sete mil, seiscentos e cinquenta e cinco) presos, tem-se uma capacidade do sistema de 357.219 (trezentos e
} 
A falta de legitimidade dos comandos da Carta Magna, a torná-la mera folha de papel nos dizeres de Lassale (2000), implica o que hodiernamente se reconhece como inconstitucionalidade por omissão administrativa, em violação ao valor efetividade ${ }^{7}$.

O método dedutivo permitirá enfocar como o tratamento das condições penitenciárias no Brasil deve ser compreendido à luz da concretização de políticas públicas voltadas para a defesa dos direitos fundamentais dos encarcerados e de que forma a atuação do Poder Judiciário tem sido interpretada na salvaguarda de referidos direitos, cujas bases normativas possuem uma clara destinação vinculada aos preceitos constitucionais, especialmente aqueles vinculados à dignidade humana.

Ainda no que tange à vertente teórico-metodológica, planeja-se seguir uma linha crítico-metodológica, que, nas palavras de Gustin e Dias (2006, p. 41)

\begin{abstract}
Supõe uma teoria crítica da realidade e sustenta duas teses de grande valor para o repensar da Ciência do Direito e de seus fundamentos e objeto: a primeira defende que o pensamento jurídico é tópico e não dedutivo, é problemático e não sistemático. Essa tese trabalha com a noção de razão prática e de razão prudencial para o favorecimento da decisão jurídica. A segunda tese insere-se na versão postulada pela teoria do discurso e pela teoria argumentativa. Essa linha compreende o Direito como uma rede complexa de linguagens e de significados.
\end{abstract}

Nessa toada, o primeiro tópico versará sobre as condições dos presídios no Brasil e os reflexos do tratamento degradante para o detento e para a sociedade, demonstrando como as condições prisionais vulneram a dignidade do detento e causam efeitos negativos na busca da diminuição da criminalidade. No segundo tópico, será abordada a correlação entre dignidade humana a partir de sua fundamentalidade e a concretização de políticas públicas

cinquenta e sete mil, duzentos e dezenove) vagas, constatando-se, assim, um déficit de vagas no montante de 210.436 (duzentas e dez mil, quatrocentas e trinta e seis). Em concomitância, deve-se lembrar da quantidade de prisões domiciliares no mesmo período, cujo total é de 148.000 (cento e quarenta e oito mil) pessoas. De conseguinte, ao somarmos o total de pessoas em situações privativas de liberdade (prisão domiciliar, detenção e reclusão), chegar-se-á a um total de 715.655 (setecentas e quinze mil, seiscentas e cinquenta e cinco) pessoas presas, incrementando o déficit de vagas para 358.219 (trezentas e cinquenta e oito mil, duzentas e dezenove) (2014, p. 17). Os números citados a título de exemplificação (correspondentes ao ano de 2014, porque foi o último levantamento realizado pelo Conselho Nacional de Justiça) demonstram que se todas as pessoas fossem presas, haveria falta, como visto, de 732.427 (setecentas e trinta e duas mil, quatrocentas e vinte e sete) vagas, a evidenciar uma situação de omissão inadmissível por parte do Poder Público, vez que francamente violadora dos direitos fundamentais dos envolvidos com este, assim, prejudicado sistema penitenciário.

${ }^{7}$ Em sentido geral, decorre necessariamente do reconhecimento de que a Constituição não é uma carta exortativa, mas, sobretudo, norma dotada de supremacia e imperatividade no plano interno para a efetivação dos seus comandos. Nesse ponto, para que se possa cogitar de inconstitucionalidade omissiva há que se reconhecer a força normativa da Constituição, além da existência de uma estrutura normativo-institucional incumbida de constatar suas eventuais violações e que contemple institutos para serem sanadas ou para impor a quem de direito que as suprima. A omissão normativa, dessa forma, em seu sentido mais amplo deve ser entendida não só pelo "não legislar", mas também pelo fato de o Poder Público não adotar medidas efetivas para alteração da realidade fática inconstitucional, a se mostrar permanente e sistêmica em violação da concreção dos direitos fundamentais da população. 
garantistas a justificar a atuação do Poder Judiciário na adoção de medidas para salvaguardar direitos fundamentais das minorias omitidos.

Posteriormente, nos terceiro e quarto tópicos se analisará a temática envolvendo o que a Corte Colombiana denominou de "estado de coisas inconstitucional”, mediante auxílio da doutrina para verificação do contexto em que se legitima sua aplicação para garantir o direito à dignidade dos reclusos no Brasil, inclusive consoante a jurisprudência precursora sobre o tema, à luz dos julgamentos do Recurso Extraordinário (RE) n. 592.581 (STF, 2015a) e do pedido de Medida Cautelar na Ação de Descumprimento Fundamental n. 347 pelo Supremo Tribunal Federal (2015b).

\title{
1. CONDIÇÕES DOS PRESÍDIOS NO BRASIL E OS REFLEXOS DO TRATAMENTO DEGRADANTE PARA O DETENTO E A SOCIEDADE
}

\begin{abstract}
A Comissão Interamericana de Direitos Humanos (2011, p. 4-5) consignou que
quando os cárceres não recebem a atenção e os recursos necessários, a sua função se distorce e, em vez de proporcionarem proteção, se convertem em escolas da delinquência e comportamento antissocial, que propiciam a reincidência em vez da reabilitação.
\end{abstract}

Segundo Mendes (2015), há uma falência crônica do sistema prisional ${ }^{8}$, decorrente de uma série de fatores, tais como prevalência de prisões provisórias em detrimento de outras medidas ${ }^{9}$, a excessiva demora nos julgamentos, a aplicação de penas privativas de liberdade a crimes de menor gravidade, medidas essas justificadas pela cultura do aprisionamento como solução para impunidade, segundo o CNJ - Conselho Nacional de Justiça (2014).

Mas não só por esses fatores as prisões se tornaram locais de expiação cruel do detento, quer seja provisório, quer seja definitivo ${ }^{10}$. De acordo com o CNMP - Conselho Nacional Ministério Público (2013a), tomando por base relatório que elaborou (2013b)

Os 1.598 estabelecimentos inspecionados possuem capacidade para 302.422 pessoas, mas abrigavam, em março de 2013, um total de 448.969 presos. O déficit é de 146.547 ou $48 \%$. A superlotação é registrada em todas as regiões do país e em todos

\footnotetext{
${ }^{8}$ Em entrevista jornalística, um ex-Ministro de Estado admitiu que as prisões brasileiras são verdadeiras "masmorras medievais", confessando que preferiria até morrer a ser preso numa delas (O Globo, 2012).

${ }^{9}$ De acordo com dados do Conselho Nacional de Justiça (2014), 41\% (quarenta e um por cento) dos presos no Brasil são provisórios.

10 Em paralelo, algumas questões relacionadas à segurança pública têm ganhado grande visibilidade, principalmente quanto à degradação das áreas públicas, à elevação da criminalidade e do senso comum sobre a insegurança (maxime nos centros urbanos), bem como quanto aos obstáculos de uma adequada reforma das instituições de gestão da justiça criminal, de combate e prevenção à violência policial, superlotação dos presídios e más condições de internação de jovens recalcitrantes, entre tantos outros problemas a serem enfrentados.
} 
os tipos de estabelecimento (penitenciárias, cadeias públicas, casas do albergado, etc). O déficit de vagas é maior para os homens. O sistema tem capacidade para 278.793 pessoas do sexo masculino, mas abrigava 420.940 homens presos em março de 2013. Para as mulheres, são 23.629 vagas para 28.029 internas.

Separações.

As inspeções verificaram que a maior parte dos estabelecimentos não faz as separações dos presos previstas na Lei de Execuções Penais. Segundo o relatório, 1.269 (79\%) estabelecimentos não separam presos provisórios de definitivos; 1.078 (67\%) não separam pessoas que estão cumprindo penas em regimes diferentes (aberto, semiaberto, fechado); 1.243 (quase 78\%) não separam presos primários dos reincidentes. Em 1.089 (68\%) locais, não há separação por periculosidade ou conforme o delito cometido; em 1.043 (65\%), os presos não são separados conforme facções criminosas. Há grupos ou facções criminosos identificados em 287 estabelecimentos inspecionados $(17 \%)$.

Fugas, integridade física dos presos e disciplina.

Entre março de 2012 e fevereiro de 2013, foram registradas 121 rebeliões, 23 das quais com reféns. Ao todo, houve 769 mortes, das quais 110 foram classificadas como homicídios e 83 como suicídios. Foram registradas 20.310 fugas, com a recaptura de 3.734 presos e o retorno espontâneo de 7.264. Os casos em que presos, valendo-se de saída temporária não vigiada, não retornam na data marcada, são computados como fuga ou evasão. Houve apreensão de drogas em 654 locais, o que representa cerca de $40 \%$ dos estabelecimentos inspecionados.

No quesito disciplina, o relatório mostra que 585 estabelecimentos (37\%) não observam o direito de defesa do preso na aplicação de sanção disciplinar. Em 613 locais $(38 \%)$, o ato do diretor da unidade que determina a sanção não é motivado ou fundamentado; em 934 (5\%), nem toda notícia de falta disciplinar resulta em instauração de procedimento. As sanções coletivas foram registradas em 116 estabelecimentos (7\%). Em $211(13 \%)$ locais não é proporcionada assistência jurídica e permanente; em 1.036 (quase 65\%), não há serviço de assistência jurídica no próprio estabelecimento.

Assistência material, saúde e educação.

Quase metade dos estabelecimentos (780) não possui cama para todos os presos e quase um quarto (365) não tem colchão para todos. A água para banho não é aquecida em dois terços dos estabelecimentos (1.009). Não é fornecido material de higiene pessoal em 636 (40\%) locais e não há fornecimento de toalha de banho em 1.060 (66\%). A distribuição de preservativo não é feita em 671 estabelecimentos (42\%). As visitas íntimas são garantidas em cerca de dois terços do sistema (1.039 estabelecimentos).

Cerca de $60 \%$ dos estabelecimentos (968) não contam com biblioteca; falta espaço para prática esportiva em 756 locais $(47 \%)$ e para banho de sol (solário) em 155 $(10 \%)$

A segunda edição do referido relatório (2016b) por parte do CNMP - Conselho

Nacional Ministério Público, traz seus escopos e embasa a sua opinião sobre as necessidades do sistema prisional pátrio (2016a)

A divulgação dos dados atende a dois ingentes propósitos.

O primeiro, conclamar o Ministério Público brasileiro, e todas as demais instituições que compõem o Sistema de Justiça nacional, a otimizar o manejo dos mecanismos legais, judiciais e administrativos disponíveis, para a superação da dramática realidade carcerária no País. $\mathrm{O}$ confronto com números preocupantes, como estes que se apresentam, impõe não apenas indagações quanto ao que deve ser feito e como deve sê-lo, mas exige, em tributo ao dever constitucional de eficiência, o compromisso com os resultados transformadores pelos quais tanto ansiamos. Para muito além da indignação, ecoada em milhares de vozes clamando por melhorias nas condições do sistema 
prisional no país, o dever de ofício nos compele, a todos, a ações concretas e eficazes. Nesse sentido, o Programa Segurança sem Violência, iniciativa do Conselho Nacional do Ministério Público, é uma importante referência de coalizão interinstitucional, com a fixação de claros objetivos e prazos para o seu cumprimento, visando ao aperfeiçoamento da infraestrutura, da gestão e da legislação referente ao sistema prisional.

$\mathrm{O}$ segundo propósito consiste no atendimento ao princípio da publicidade e ao dever de transparência, municiando a sociedade com amplo retrato sobre a difícil realidade prisional que ela conhece, em fragmentos, por meio do noticiário.

Os números estampam a necessidade de assegurar, o quanto antes, o cumprimento de pena no país condizente com a dignidade da pessoa humana, assegurada a integridade dos apenados e dos seus familiares, e a possibilidade de verdadeira ressocialização.

O clamor popular, as cobranças da mídia e da opinião pública por soluções imediatas levam muitas vezes o legislador ao caminho mais fácil ${ }^{11}$. Este fenômeno, não só perceptível no Brasil, recebeu o nome por Silva Sanchéz (2001. p. 20) de expansionismo penal

Pois bem, contra tais posições doutrinárias na verdade, não é difícil verificar a existência de uma tendência claramente dominante na legislação de todos os países para a introdução de novas infrações e a um agravamento das já existentes, que pode ser classificado dentro do quadro geral da restrição, ou "reinterpretação" das garantias clássicas do direito penal substantivo e direito processual penal. Criação de espaços de expansão e novos " 'bens jurídico-penais riscos legais e criminais relevantes, facilitam as regras de atribuição e de relativização de princípios político-criminales de garantia não seriam senão aspectos desta tendência geral, os quais deve ser feita ainda referência ao termo "expansão"12

Ao assim agir (ou deixar de agir), além de não se ofertar contribuição para a diminuição da criminalidade, tampouco ataca a sua causa, apenas agrava-se o problema da superlotação e do caos vivenciado pelos encarcerados. Esta é a conclusão de Boldt (2013, p 124)

A assunção da sanção penal como instrumento primordial na solução de conflitos não apenas agrava o processo auto-destrutivo do direito penal, mas impulsiona a edificação do Estado penal, paradigma contrário ao Estado de direito e que inviabiliza a universalização dos direitos e garantias fundamentais.

Durante o cumprimento da pena definitiva, os presos têm seus direitos políticos suspensos, além de serem um grupo impopular na sociedade ${ }^{13}$. Esses ingredientes somados

\footnotetext{
${ }^{11}$ Aumenta-se a pena do delito. Transforma-o em hediondo. Agrava-se o cumprimento da pena. Age-se como se o problema tivesse solução simplista.

12 No original: Pues bien, frente a tales posturas doctrinales en efecto no es nada difícil constatar la existencia de una tendencia claramente dominante en la legislación de todos los países hacia la introducción de nuevos tipos penales así como a una agravación de los ya existentes, que cabe enclavar en el marco general de la restricción, o la «reinterpretación» de las garantías clásicas del Derecho penal sustantivo y del Derecho procesal penal. Creación de nuevos «bienes jurídico-penales», ampliación de los espacios de riesgos jurídico-penalmente relevantes, flexibilización de las reglas de imputación y relativización de los principios político criminales de garantía no serían sino aspectos de esta tendencia general, a la que cabe referirse con el término «expansión» ${ }^{13}$ Como os presidiários não são um grupo que contam com apoio da sociedade, não votam quando condenados definitivamente (enquanto perdurar a pena) e naturalmente não são bem quistos, as mazelas prisionais não foram
} 
aos que acima mencionados, conduzem à receita para que seus direitos fundamentais ${ }^{14}$ sejam violados ${ }^{15}$ sem que haja um repúdio pela silenciosa maioria, que aceita as aviltantes condições do sistema carcerário ${ }^{16}$.

O quadro caótico do sistema prisional conduz não somente à degradação do preso, como também agrava o problema de segurança pública ${ }^{17}$, gerando mais violência, muitas das vezes decorrente dos maus tratos a que os detentos foram submetidos quando da restrição de sua liberdade. Preciso, a respeito, o pensamento de Foucault (2009, p. 62)

o sentimento de injustiça que um prisioneiro experimenta é uma das causas que mais podem tornar indomável seu caráter. Quando se vê assim exposto a sofrimentos que a lei não ordenou nem mesmo previu, ele entra num estado habitual de cólera contra tudo o que o cerca; só vê carrascos em todos os agentes da autoridade: não pensa mais ter sido culpado; acusa a própria justiça.

Essa perniciosa permanência de desrespeito dos direitos fundamentais por parte do Poder Público tem recebido a denominação, pela doutrina e jurisprudência, de "estado de coisas inconstitucional", cuja supressão, a cargo do Poder Judiciário, tem sido defendida para efetivação de políticas públicas omitidas pela Administração Pública, as quais, quando concretizadas, asseguram tais direitos.

\section{A CORRELAÇÃo ENTRE DIGNIDAde hUMANA A PARTIR DE SUA FUNDAMENTALIDAde E A CONCRETIZAÇÃo DE POLÍticas PÚbliCas GARANTISTAS}

O Estado, pelo planejamento e gestão financeira, tem a incumbência de promoção de políticas públicas. Nos termos constitucionais do art. 84, inciso XXIII, compete ao Presidente da República enviar ao Congresso Nacional o plano plurianual, o projeto de lei de diretrizes

alvo, ainda, da necessária atenção pública para que a pena possa, sim, ser cumprida nos limites da lei, sem que se transformasse em medida de tortura e indignidade.

${ }^{14}$ A Constituição Federal garante o princípio da dignidade da pessoa humana (art. $1^{\circ}$, III), proíbe a tortura e o tratamento desumano ou degradante (art. 50, III), veda as sanções cruéis (art. 5, XLVII, "e"), impõe o cumprimento da pena em estabelecimentos distintos, de acordo com a natureza do delito, a idade e sexo do apenado (art. $5^{\circ}$, XLVIII), assegura aos presos o respeito à integridade física e moral (art. $5^{\circ}$, XLIX) e prevê a presunção de inocência (art. $\left.5^{\circ}, \mathrm{LVII}\right)$.

${ }^{15}$ As penitenciárias no Brasil não se revelam como meios de punição e nem de ressocialização da pessoa, mas de degradação, humilhação e expiação, violando expressamente os postulados da dignidade humana insculpidos em nossa Constituição.

${ }^{16}$ Daí o papel relevante que o Supremo Tribunal Federal deve exercer para garantia dos prefalados direitos, por ser o Judiciário, dentre os poderes da República, o menos susceptível às influências e preferências políticas.

17 Não obstante as prisões estejam cada vez mais superlotadas, o Poder Público, provavelmente pela aceitação social deste estado de barbárie, não vem adotando medidas para a efetiva correção do problema. 
orçamentárias e as propostas de orçamento previstos na Constituição. A seu turno, o art. 165, incisos I, II, e III, da Constituição Federal estabelece que leis de inciativa do Poder Executivo deverão adotar o plano plurianual, as diretrizes orçamentárias e os orçamentos anuais ${ }^{18}$.

$\mathrm{O}$ art. $8^{\circ}$, da lei de Responsabilidade Fiscal, estipula que em até trinta dias após à publicação dos orçamentos, nos termos em que dispuser a lei de diretrizes orçamentárias e observado o disposto na alínea c, do inciso I, do art. $4^{\circ}$, o Poder Executivo estabelecerá a programação financeira e o cronograma de execução mensal de desembolso. Logo, a priori, ao Poder Executivo está reservada a implementação e execução das políticas públicas.

No entanto, consoante afirma Dantas (2015), no cenário político atual verifica-se que muitas das prioridades governamentais constantes do orçamento são tratadas com base em trocas pela aprovação dos projetos de interesse do Executivo, situação a qual instala um desvio de finalidade na programação, gestão e execução orçamentárias, ao não se aplicarem os recursos prioritários para as políticas públicas estabelecidas em planejamento estatal ${ }^{19}$.

Ao contrário disso, a elaboração, gestão e execução das políticas públicas deve ser, numa primeira análise, fruto de prioridades políticas dentre as diversas necessidades do Estado. Sua implementação demanda, ainda, a utilização de recursos orçamentários, naturalmente finitos e deficitários.

Todavia, a inércia proposital ou a finitude dos recursos não pode servir de pretexto para que uma política pública não seja executada, como no caso das penitenciárias brasileiras $^{20}$. O Poder Judiciário, nestes casos extremos, como asseverou Lewandowski em voto proferido no Recurso Extraordinário n.592.581 (STF, 2015a), é chamado para exercer o

\footnotetext{
${ }^{18}$ A menção feita a tais dispositivos constitucionais torna-se necessária para demonstrar que, apesar de o Poder Judiciário e o Poder Legislativo encaminharem suas propostas orçamentárias ao Poder Executivo para que este as inclua no orçamento geral, cabe-lhe a inciativa de apresentá-lo ao Congresso Nacional.

${ }^{19}$ Não raro se utilizam de expedientes visando à readequação do orçamento às contingências políticas do momento. Podem-se citar a abertura de créditos adicionais, de reserva de contingência e contingenciamento de despesas. A utilização dessas ferramentas, muita das vezes, se prestam como instrumento de barganha com o Legislativo para a aprovação de certas matérias de interesse do Executivo, em troca de liberação de verbas para rubricas orçamentárias de interesse dos parlamentares. Trata-se de situação advinda do denominado presidencialismo de coalizão na dicção de Abranches (1988; 2007), no qual o Presidente conquista bases de apoio no Congresso Nacional por meio de nomeações de membros dos partidos com representação no parlamento em cargos estratégicos na Administração. Como contrapartida, obtém o apoio dos partidos ou da bancada beneficiada para que sua proposta orçamentária seja aprovada, ainda que com algumas rubricas que reflitam interesses meramente locais de tais parlamentares.

${ }^{20} \mathrm{O}$ descompromisso político e o descumprimento dos direitos da população carcerária são sistêmicos, frequentes e se espalharam por todos os Estados federados. Como já mencionado, boa parte da sociedade brasileira não se importa com as situações dos presídios e os presos não detêm força para que os políticos se preocupem em alterar o bárbaro estado das prisões, as quais se tornaram locais de constante aviltamento dos postulados regentes da dignidade da pessoa humana.
} 
(...) $\mathrm{Na}$ verdade há uma grande maioria de pessoas, soi-dissant "de bem", que simplesmente não deseja o regresso de tais indivíduos na sociedade. Olvidam-se, contudo, que esse retorno, um dia, fatalmente ocorrerá. Por isso, não é mais possível adiar o necessário debate consistente em antecipar as medidas para que os egressos do sistema prisional tenham a efetiva possibilidade de reinserção na vida social, seja ele travado por simples pragmatismo, quer dizer, baseado em considerações de segurança pública, seja ainda por mero espírito humanitário, isto é, motivado pelo benfazejo amor ao próximo.

A função do Estado não é apenas preservar a dignidade humana contra atos atentatórios (Sarmento, 2000), mas também, no caso versado, de agir em supressão da omissão e desídia devastadoras para os encarcerados. Barroso (2007, p. 11-12; 2007, p. 46) demonstra que em casos tais, há uma imposição constitucional no sentido de que o Judiciário aja, não por convicção pessoal do julgador, mas para a proteção de minorias que têm seus direitos vulnerados, embora constitucionalmente assegurados

\begin{abstract}
Mas pode acontecer de a maioria política vulnerar direitos fundamentais. Quando isto ocorre, cabe ao Judiciário agir. É nesse ambiente, é nessa dualidade presente no Estado constitucional democrático que se coloca a questão essencial: podem juízes e tribunais interferir com as deliberações dos órgãos que representam as maiorias políticas - isto é, o Legislativo e o Executivo -, impondo ou invalidando ações administrativas e políticas públicas? A resposta será afirmativa sempre que o Judiciário estiver atuando, inequivocamente, para preservar um direito fundamental previsto na Constituição ou para dar cumprimento a alguma lei existente. Vale dizer: para que seja legítima, a atuação judicial não pode expressar um ato de vontade própria do órgão julgador, precisando sempre reconduzir-se a uma prévia deliberação majoritária, seja do constituinte, seja do legislador. E é nesse sentido que agregam muita importância os princípios na bandeira do Pós-Positivismo. Tratam-se de princípios que limitam o poder do Estado e protegem os cidadãos contra a opressão geralmente cometida por aqueles que detêm o poder. Nesse mesmo contexto, foram consagrados nas Constituições valores outros, como os direitos sociais - saúde, educação, segurança, lazer, moradia. Estes, para serem efetivados, demandam uma prestação positiva do Poder Público, por meio de leis e comportamento do Poder Executivo.
\end{abstract}

Assim, quando se detecta uma omissão estatal na implementação de política pública destinada a garantir direitos fundamentais, entende-se que pode haver atuação do Judiciário na adoção de medidas cabíveis para sanar tal lacuna, ainda que esta situação gere posicionamentos contrários que se baseiem na interdependência funcional como desdobramento do princípio da separação de poderes, impactando não só na questão das competências constitucionalmente determinadas, mas também na própria formulação e implementação de políticas públicas.

A intervenção do Judiciário ocorre não só em matéria de clara vertente constitucional garantidora de preceito fundamental de dignidade humana, mas também em questões afetas a distintas políticas públicas, e. g., no caso do meio ambiente, em que pode-se citar decisão do 
Supremo Tribunal Federal em sede de Recurso Extraordinário $\mathrm{n}^{\circ}$ 643.435 (2013), sob relatoria de Fux, ao discutir a responsabilidade do Município de Carazinho (RS) no tocante à obrigação de fazer, configurada na elaboração, pelo Município, de plano de gerenciamento integrado de resíduos da construção civil. Em tal julgado, reiterou-se a jurisprudência da Corte com transcrição de relevantes excertos extraídos do julgado da ADPF n. 45 - MC (STF, 2004), sob a relatoria de Mello

Se o Estado deixar de adotar as medidas necessárias à realização concreta dos preceitos da Constituição, em ordem a torná-los efetivos, operantes e exequíiveis, abstendo-se, em conseqüência, de cumprir o dever de prestação que a Constituição lhe impôs, incidirá em violação negativa do texto constitucional. Desse non facere ou non praestare, resultará a inconstitucionalidade por omissão, que pode ser total, quando é nenhuma a providência adotada, ou parcial, quando é insuficiente a medida efetivada pelo Poder Público.

(...) A omissão do Estado - que deixa de cumprir, em maior ou em menor extensão, a imposição ditada pelo texto constitucional - qualifica-se como comportamento revestido da maior gravidade político-jurídica, eis que, mediante inércia, o Poder Público também desrespeita a Constituição, também ofende direitos que nela se fundam e também impede, por ausência de medidas concretizadoras, a própria aplicabilidade dos postulados e princípios da Lei Fundamental (grifos no original).

Ainda, na mesma decisão (STF, 2013) fez-se menção à questão da intervenção do Poder Judiciário na implementação de políticas públicas, ou seja, a interferência do Poder Judiciário sobre a adoção e aplicação das políticas públicas em face da ausência ou "ineficiência" do Legislativo ou do Executivo em concretizar os direitos fundamentais, entre estes a dignidade humana. Para tanto, a Corte Suprema do Brasil reafirmou no Recurso supracitado (2013) outros excertos extraídos do julgado da ADPF n. 45 - MC (STF, 2004)

É certo que não se inclui, ordinariamente, no âmbito das funções institucionais do Poder Judiciário - e nas desta Suprema Corte, em especial - a atribuição de formular e de implementar políticas públicas (JOSÉ CARLOS VIEIRA DE ANDRADE, 'Os Direitos Fundamentais na Constituição Portuguesa de 1976', p. 207, item n. 05, 1987, Almedina, Coimbra), pois, nesse domínio, o encargo reside, primariamente, nos Poderes Legislativo e Executivo. Tal incumbência, no entanto, embora em bases excepcionais, poderá atribuir-se ao Poder Judiciário, se e quando os órgãos estatais competentes, por descumprirem os encargos político-jurídicos que sobre eles incidem, vierem a comprometer, com tal comportamento, a eficácia e a integridade de direitos individuais e/ou coletivos impregnados de estatura constitucional, ainda que derivados de cláusulas revestidas de conteúdo programático. (...) (RE n. 134.297, Relator o Ministro Celso de Mello, $1^{\text {a }}$ Turma, DJ de 22.9.95) (grifos no original).

Demonstra-se, assim, como a atuação do Poder Judiciário no Brasil pode resultar em concretização de direitos fundamentais, maxime quando se trata da dignidade do ser humano ${ }^{21}$,

\footnotetext{
${ }^{21}$ No que tange à dignidade humana, uma de suas mais clássicas concepções se refere à proteção da condição propriamente humana, dos elementos constitutivos da pessoa como realidade física, psíquica e moral, e é por isso
} 
considerada não apenas como pedra angular na qual se assentam os demais valores protegidos pelo Direito, mas, também, capaz de elevá-lo (ser humano), sob uma visão kantiana, acima de qualquer precificação ou equivalência

No reino dos fins, tudo tem um preço ou uma dignidade. Quando uma coisa tem um preço, pode pôr-se, em vez dela qualquer outra coisa como equivalente; mas quando uma coisa está acima de todo o preço, e, portanto, não permite equivalente, então ela tem dignidade. (Kant, 2008, p. 77)

Desse modo ressalta Millán Puelles (1976, p.98-99)

A dignidade da pessoa humana tem o mesmo fato radical em seu alcance absoluto. $\mathrm{E}$, como corolário, o respeito a esse factum pessoal é o que intrínseco e objetivamente se considera como um verdadeiro axioma que, como tal, não está condicionado humanamente por fatores de tipo individual nem de índole histórica ${ }^{22}$

E segue o autor afirmando (Millán Puelles, 1976, p. 99)

quando se fala, geralmente, da dignidade da pessoa humana, não se deve pensar apenas no valor dos homens que atuam corretamente, mas em todo e qualquer homem, pelo fato de ser uma pessoa, que tem uma categoria superior à de qualquer ser irracional ${ }^{23}$

Ao considerar a dignidade como valor ontológico que ultrapassa a vontade humana e a própria racionalidade que é inerente ao homem, os autores afirmam a existência de uma universalidade e globalidade ínsita a ele, as quais compreenderão não só a razão, como todo o organismo e suas manifestações psicossomáticas. Esta compreensão do "todo" como condição sine qua non é imprescindível para que a dignidade alcance um grau absoluto e inarredável de proteção $^{24}$.

\footnotetext{
que, quiçá, resulta num dos conceitos jurídicos mais difíceis de definir. Mesmo que não se possa aqui aprofundar sobre o conceito filosófico da dignidade e em seu caráter prepositivo ou não, não se deve deixar de assinalar que o seu reconhecimento positivado nos diferentes países tem sido, em grande parte, influenciado pelas diferentes correntes filosóficas e religiosas que atribuem ao ser humano certos fins e que lhe reconhecem, em maior ou menor medida, autonomia para formar livremente sua vontade e atuar de acordo com ela, de sorte a ser reconhecido como "sujeito" e não como "objeto" dos acontecimentos e das situações (Gómes Sánchez, 2005).

${ }^{22}$ No original: La dignidad de la persona humana es la de ese mismo hecho radical en su alcance absoluto. Y, correlativamente, el respeto a ese factum personale es el que intrínseca y objetivamente se merece un verdadero áxion que, como tal, no está condicionado humanamente por factores de tipo individual ni de índole histórica.

${ }^{23}$ No original: cuando se habla, en general, de la dignidad de la persona humana, no se piensa tan solo en el valor de los hombres que actúan rectamente, sino en que todo hombre, por el hecho de ser una persona, tiene una categoría superior a la de cualquier ser irracional.

${ }^{24} \mathrm{O}$ respeito à dignidade supõe, de conseguinte, o respeito a todas as dimensões, quer sejam corporais (físicas e materiais), psíquicas e racionais. Ora, ao considerar a situação vivenciada atualmente pelos encarcerados nas penitenciárias brasileiras, inclusive conforme os dados anteriormente apresentados, torna-se claro que há evidente e inafastável afronta à sua dignidade.
} 
Diante desse quadro, os direitos fundamentais necessitam ser observados sob uma nova perspectiva - a da dignidade humana -, com o desiderato de conferir-lhes maior efetividade na árdua tarefa de se proteger os indivíduos e a sociedade ${ }^{25}$.

A nova compreensão da Constituição trouxe consigo importantes reflexos sobre o ordenamento jurídico e, especialmente, sobre a correlação entre políticas públicas e proteção dos direitos fundamentais ${ }^{26}$.

Se no positivismo jurídico os princípios eram destituídos de força normativa, sendolhes atribuída função meramente subsidiária, no pós-positivismo jurídico há uma mudança de compreensão, especialmente em razão do reconhecimento de que eles são inequivocamente dotados de força normativa ${ }^{27}$.

O fenômeno da constitucionalização, no qual se encontra inserida a temática da eficácia dos direitos fundamentais e sua consequente aplicação nas políticas públicas, trouxe importantes reflexos para o ordenamento jurídico, conferindo-lhe sistematicidade e unidade. Em razão deste fenômeno, as normas constitucionais se tornaram fundamento de toda e qualquer norma infraconstitucional integrantes dos diversos segmentos do direito.

Como tal, o neoconstitucionalismo ancora-se em três premissas elementares que se fundam no objetivo maior de dotar de máximo grau de eficácia, e consequente efetividade, as políticas públicas voltadas para a proteção do ser humano ${ }^{28}$. Nessa linha de pensamento, segundo Barcellos (2005, p. 84-85)

\footnotetext{
${ }^{25} \mathrm{~A}$ partir deste novo enfoque, busca-se ampliar o lastro protetivo atribuído aos indivíduos, pois os direitos fundamentais deixam de ser concebidos exclusivamente como limites à atuação do Poder Público, para também imporem prestações positivas por parte do Estado que deve assegurar grau máximo de concretização de tais direitos.

${ }^{26} \mathrm{O}$ reconhecimento da força normativa e da supremacia do texto constitucional, com a sobrelevação da importância dos princípios constitucionais, destacadamente em razão da sua capacidade para promover a unidade, sistematicidade e harmonia ao ordenamento jurídico, fomentou o desenvolvimento do fenômeno denominado pós-positivismo fundamentado no neoconstitucionalismo.

${ }^{27}$ Com a mudança de perspectiva, as normas constitucionais passam a irradiar seus efeitos por todo ordenamento jurídico, conformando a elaboração e interpretação da fundamentalidade dos direitos em prol da dignidade humana.

${ }^{28} \mathrm{O}$ reconhecimento de uma normatividade subjacente à própria ideia de comando a ser observado e, portanto, concretizado quanto às normas constitucionais, representa a primeira premissa que se caracteriza, então, pela imperatividade; num segundo aspecto, a força motriz do sistema se baseia na constatação de que a superioridade da Constituição irradia efeitos sobre todo o sistema jurídico, enlaçando-o aos seus dispositivos de modo que não poderá haver antinomia amparada em dispositivo contrário à Constituição; e, por último, a terceira premissa se assenta na reformulação dos métodos interpretativos que se dirigem à manifestação do Poder inexorável da Constituição, determinando sempre uma interpretação conforme seus dispositivos (Barcellos, 2005). Desse modo, ao interrelacionarem-se os aspectos centrais das condições em que se encontram as penitenciárias no Brasil, os direitos dos encarcerados e a concretização do princípio da dignidade humana, todos como parte integrante de uma política pública de segurança nacional, revela-se que a atuação do Judiciário em prol da sua defesa se forja
} 
O neoconstitucionalismo vive essa passagem, do teórico ao concreto, de feérica, instável e em muitas ocasiões inacabada construção de instrumentos por meio dos quais se poderá transformar os ideais da normatividade, superioridade e centralidade da Constituição em técnica dogmaticamente consistente e utilizável na prática jurídica

Verifica-se, assim, que no caso das penitenciárias no Brasil, o reconhecimento da sua situação hodierna como inconstitucional, com a imposição de medidas para correção dos seus graves problemas, é, em si, algo que não avança na seara do Poder Legislativo ou do Poder Executivo, mas almeja a salvaguarda dos direitos mínimos dos encarcerados ${ }^{29}$.

\section{O "ESTADO DE COISAS INCONSTITUCIONAL": UMA ANÁLISE DOUTRINÁRIA E JURISPRUDENCIAL}

Hodiernamente não se defende mais que o Poder Judiciário apenas cumpra sua função de resolver litígios inter partes, isto é, aplicar meramente a lei penal, dizer o direito em relações privadas ou, ainda que públicas, restritas ao que somente interessa às partes.

Nesse ponto, colaciona-se lição de Grinover, Lucon e Watanabe (2015)

O Judiciário brasileiro, há muito tempo, deixou de cumprir apenas a função que tradicionalmente lhe é atribuída — resolver com justiça litígios individuais de caráter patrimonial - para assumir também um papel de destaque no cenário político, assegurando, diante da inércia e da ineficácia de atuação dos outros poderes estatais, a efetivação de direitos e de garantias fundamentais previstos na Constituição de 1988

O Judiciário passa de uma função passiva para se tornar um Poder que adentra no campo político para assegurar o cumprimento dos direitos e garantias fundamentais previstos na Constituição Federal, estando, para tanto, algumas das vezes autorizado a avançar no terreno da concretização de políticas públicas, visando salvaguardar direitos e garantias fundamentais, prioritariamente das minorias ${ }^{30}$.

Conforme bem ressalta Pereira e Gonçalves (2015, p. 145)

A implementação dos direitos sociais é uma matéria que guarda conexão estrita com o tema das omissões. A crescente judicialização desses direitos - bem como

em um comando constitucional de inarredável observância, que se ampara e justifica nas premissas acima referidas.

${ }^{29}$ Não se tratam de violações esporádicas que mereceriam respostas individuais e também um atuar frágil e ineficiente por parte do Estado. As violações aos direitos dos presidiários se tornaram regra, demonstrando a ausência de uma política pública voltada para os parâmetros constitucionalmente determinados.

${ }^{30}$ No Brasil há uma farta exemplificação de coisas inconstitucionais. Entretanto, o caso do sistema prisional revela um quase total descompromisso político-jurídico com a resolução do problema e uma afronta concreta a postulados constitucionais e normas infraconstitucionais, fazendo com que a dignidade do preso seja considerada como quase inexistente. 
acolhimento das demandas pelo Judiciário - traz implícita a concepção de que os entes públicos não adimpliram seu dever de materializar os comandos constitucionais, ou seja, pressupõe o reconhecimento de omissões materiais inconstitucionais.48 Vale destacar, ainda, que o STF tem apreciado um amplo espectro de situações envolvendo omissões não normativas tendo como parâmetro direto normas constitucionais programáticas, rejeitando a visão de que elas demandariam inexoravelmente interpositio legislatoris para produzirem efeitos e se tornarem vinculantes. O impacto desse quadro na visão legiscêntrica da omissão inconstitucional é evidente, ao retirar do parlamento o monopólio da atenção sobre o dever de cumprimento da Constituição. Também outros entes, como órgãos executivos, entram em foco. Com isso, a análise da atuação de todos os agentes públicos é alçada à condição de objeto de controle de constitucionalidade em processos objetivos.

Além disso, a discussão sobre uma definição rígida de política pública não se encontra ainda pacificada na doutrina. A reestruturação do Estado visando conferir melhores condições sociais aos indivíduos foi o grande impulso que fez com que seu estudo passasse a ganhar relevância na seara do Direito. Nesse sentido, segundo Bucci (2006, p. 39) ${ }^{31}$

política pública é o programa de ação governamental que resulta de um processo ou conjunto de processos juridicamente regulados - processo eleitoral, processo de planejamento, processo de governo, processo orçamentário, processo legislativo, processo administrativo, processo judicial - visando coordenar os meios à disposição do Estado e as atividades privadas, para a realização de objetivos socialmente relevantes e politicamente determinados. Como tipo ideal, a política pública deve visar a realização de objetivos definitivos, expressando a seleção de prioridades, a reserva de meios necessários à sua consecução e o intervalo de tempo em que se espera o atingimento dos resultados

Dessa maneira, se há evidentemente uma lacuna ou omissão em relação ao descumprimento das políticas públicas que deveriam adotar-se pelo Estado, no exercício de seus poderes constituídos, poderá questionar-se, no plano jurisdicional, como tal descumprimento poderá ser sanado, visando a efetivar os direitos e garantias fundamentais. Nos dizeres de Miranda (2012, p. 11) ao reconhecer a possibilidade de multiplicidade de fontes de omissão (normativa, legislativa, política, entre outras)

Relativamente a quaisquer funções do Estado objeto de disciplina pela Constituição, não custa surpreender manifestações possíveis - e não apenas teóricas - de comportamentos omissivos, sejam omissões de atos normativos, sejam de atos de conteúdo não normativo ou individual e concreto. Sucede isto com a função legislativa e com a função política ou de governo e, em alguns casos, com a revisão constitucional; sucede isto com a função administrativa e pode suceder até com a função jurisdicional. Tais comportamentos vêm, assim, a ser inconstitucionais ou ilegais, consoante os casos, e podem ainda revelar-se ilícitos.

31 Tal definição proposta, para o estudo em tela, mostra-se a mais adequada, uma vez que contempla a necessidade de que haja processos regulados para a realização dos chamados interesses públicos que se concretizem mediante ações, programas e projetos específicos voltados para a efetivação dos direitos fundamentais. 
É justamente para explicar a atuação do Judiciário ante uma omissão dos demais Poderes, notadamente no caso do Executivo, é que surge o que se vem denominando de “estado de coisas inconstitucional”, e que ainda não possui uma conceituação sólida e unívoca sobre o seu significado ${ }^{32}$, mas que pode ser compreendida a partir da análise das características apontadas pela doutrina para o reconhecimento dessa situação fática

\begin{abstract}
A) Desconhecimento reiterado e geral de direitos e liberdades fundamentais por parte das autoridades públicas. B) A adoção de práticas constitucionais por estes poderes. C) A omissão dos órgãos competentes em matéria de defesa dos direitos constitucionais ao adotar medidas corretivas das violações desses direitos. D) A manutenção de ordenamentos transitórios ou temporários em temas centrais, como a autonomia e independência do poder judicial e seu regime disciplinar. E) $O$ ativismo judicial. F) Os juízes provisórios. G) O mau funcionamento e desempenho de alguns órgãos judiciais e de defesa da proteção dos direitos fundamentais. $\mathrm{H}$ ) $\mathrm{O}$ exercício de delegação legislativa ilimitada pelo Poder Executivo. I) A impunidade para crimes de corrupção e direitos humanos. E, J) A Substituição dos mecanismos de reforma constitucional e o poder constituinte, entre outros, pela justiça constitucional $^{33}$ (Corredor, 2006, p. 343-344)
\end{abstract}

E, para o caso das penitenciárias no Brasil, estão presentes os requisitos autorizadores para a intervenção judicial, como demonstra Barcellos (2010, p. 45)

A primeira conclusão que se quer enunciar aqui, embora se trate de certo truísmo, é a de que o tratamento conferido aos presos no Brasil, e descrito antes, viola de forma grosseira os direitos humanos. O ponto será aprofundado adiante. A segunda conclusão a apurar é a de que a violação dos direitos humanos dos presos no Brasil constitui o tratamento normal (do ponto de vista estatístico) conferido a tal parcela da população: a rotina e não um desvio eventual. Parece certo afirmar que em qualquer sistema prisional de que se cogite, em qualquer lugar do mundo, sempre será possível observar violações eventuais aos direitos dos presos. A diferença é que em algumas partes do mundo essas violações serão uma exceção, uma anomalia a ser punida pelo direito. Como em qualquer outra área na qual os indivíduos possam exercer liberdade, sempre haverá um percentual de condutas desviantes em relação ao padrão, daí a necessidade da própria existência do direito. No Brasil, porém, a violação não é a exceção: é a regra geral. Não se trata de um desvio episódico ou localizado, mas do padrão geral observado no país como um todo. O tratamento adequado eventualmente conferido a um preso é que constitui a exceção. A terceira

\footnotetext{
32 Streck (2015), diante da abertura e fluidez do conceito do que se entende por "estado de coisas inconstitucional", adverte que toda situação onde se vislumbra o descumprimento de mandamento constitucional poderia considerar-se de natureza claramente contrária ao sistema, a depender da carga ideológica, inclusive questionando se o salário mínimo ou as altas taxas de juros em cartões de crédito não fariam parte do seu campo conceitual.

${ }^{33}$ No original: A) Desconocimiento reiterado y general de libertades y derechos esenciales por los poderes públicos. B) La adopción de prácticas constitucionales por dichos poderes. C) La omisión de los órganos competentes en materia de defensa de derechos constitucionales de adoptar las medidas correctivas de las violaciones de estos derechos. D) El mantenimiento de ordenamientos transitorios o provisionales en materias fundamentales, como el de la autonomía e independencia del poder judicial y su régimen disciplinario. E) El activismo judicial. F) La provisionalidad de los jueces. G) El funcionamiento deficiente y el poco desempeño de los organismos judiciales y de defensoría de protección de los derechos fundamentales. H) El ejercicio de la delegación legislativa ilimitada por el poder ejecutivo. I) La impunidad de delitos de corrupción y contra los derechos humanos. Y, J) La sustitución de los mecanismos de reforma constitucional y del poder constituyente, entre otros, por la justicia constitucional
} 
conclusão é a de que esse tratamento desumano conferido aos presos não constitui um evento novo na história do Brasil.

Vale ressaltar que a Corte Constitucional Colombiana tem papel de protagonista no desenvolvimento do tema, pois ao exarar a Sentencia de Unificación (SU) n. 559 ${ }^{34}$, de 1997 , declarou o "estado de coisas inconstitucional" e impôs aos municípios envolvidos o dever de encontrarem uma solução para a inconstitucionalidade em prazo razoável (Vieira Júnior, $2015)^{35}$.

\section{A APLICAÇÃO dO "ESTAdO DE COISAS INCONSTITUCIONAL" PELO SUPREMO TRIBUNAL FEDERAL}

No Brasil, o giro jurisprudencial inicial para o reconhecimento do "estado de coisas inconstitucional" pôde ser verificado no voto de Mello, relator da ADPF n. 45, em julgamento ocorrido em 29 de abril de 2004. Oportuno estampar trechos relevantes do seu voto (STF, $2004)^{36}$

(...) não posso deixar de reconhecer que a ação constitucional em referência, considerado o contexto em exame, qualifica-se como instrumento idôneo e apto a viabilizar a concretização de políticas públicas, quando, previstas no texto da Carta Política, tal como sucede no caso (EC 29/2000), venham a ser descumpridas, total ou parcialmente, pelas instâncias governamentais destinatárias do comando inscrito na própria Constituição da República.

Essa eminente atribuição conferida ao Supremo Tribunal Federal põe em evidência, de modo particularmente expressivo, a dimensão política da jurisdição constitucional conferida a esta Corte, que não pode demitir-se do gravíssimo

\footnotetext{
${ }^{34} \mathrm{Na}$ qual constatou-se a existência de descumprimento de direitos previdenciários relativos a um grupo certo de 45 (quarenta e cinco) professores de dois municípios colombianos e de um grupo não determinável ainda maior. ${ }^{35}$ A jurisprudência da Corte Colombiana foi evoluindo. Na Sentencia de Tutela (T) n.153, de 1998, foi examinado o caso atinente ao quadro de superlotação das penitenciárias. A Corte constatou que o quadro de descumprimento de direitos fundamentais era generalizado. A superlotação, a violência física, psicológica e sexual nas penitenciárias eram a regra do sistema. Por tais razões, declarou o "estado de coisas inconstitucional" e, inserindo-se no campo da concretização de política pública, ordenou que o Poder Executivo elaborasse um plano de construção e reparação das unidades carcerárias, determinando, ainda, que os recursos orçamentários necessários fossem devidamente alocados para a consecução da ordem (Vieira Júnior, 2015). Mais recentemente, na Sentencia de Tutela (T) n. 25, de 2004, a Corte apreciou 108 (cento e oito) pedidos de tutelas formulados por 1.150 (mil, cento e cinquenta) núcleos familiares deslocados, e entendeu por bem declarar o "estado de coisas inconstitucional", impondo ao Poder Executivo a formulação de novas políticas públicas, leis e um marco regulatório eficiente para proteger os direitos individuais dos demandantes (Vieira Júnior, 2015). Nesse caso, a experiência teve mais sucesso do que a ocorrida na decisão objeto da Sentença de Tutela n. 153, de 1998, porque não houve simplesmente uma imposição para que o Poder Executivo resolvesse o problema com uma maior alocação de recursos e construção de penitenciárias. As ordens foram dirigidas a um número elevado de autoridades públicas, e principalmente houve o necessário diálogo da Corte com os outros Poderes e com a sociedade sobre a adequação das medidas judiciais determinadas durante a fase de sua implementação (Vieira Júnior, 2015).

${ }^{36} \mathrm{O}$ voto demonstra como surgiu a aplicação do "estado de coisas inconstitucional" no Supremo Tribunal Federal, ainda que expressamente não houvesse recebido tal denominação àquela época.
} 
encargo de tornar efetivos os direitos econômicos, sociais e culturais - que se identificam, enquanto direitos de segunda geração, com as liberdades positivas, reais ou concretas (RTJ 164/158-161, Rel. Min. CELSO DE MELLO) -, sob pena de o Poder Público, por violação positiva ou negativa da Constituição, comprometer, de modo inaceitável, a integridade da própria ordem constitucional: "DESRESPEITO À CONSTITUIÇÃO - MODALIDADES DE COMPORTAMENTOS INCONSTITUCIONAIS DO PODER PÚBLICO. - O desrespeito à Constituição tanto pode ocorrer mediante ação estatal quanto mediante inércia governamental. (grifos no original)

Recentemente, o Plenário do Supremo Tribunal Federal, no julgamento do Recurso Extraordinário n. 592.581, ocorrido em 13 de agosto de 2015, decidiu que o Poder Judiciário pode impor à Administração Pública que realize obras ou reformas emergenciais em presídios para garantir os direitos fundamentais dos $\operatorname{presos}^{37}$. Em sua ementa tem-se (2015a)

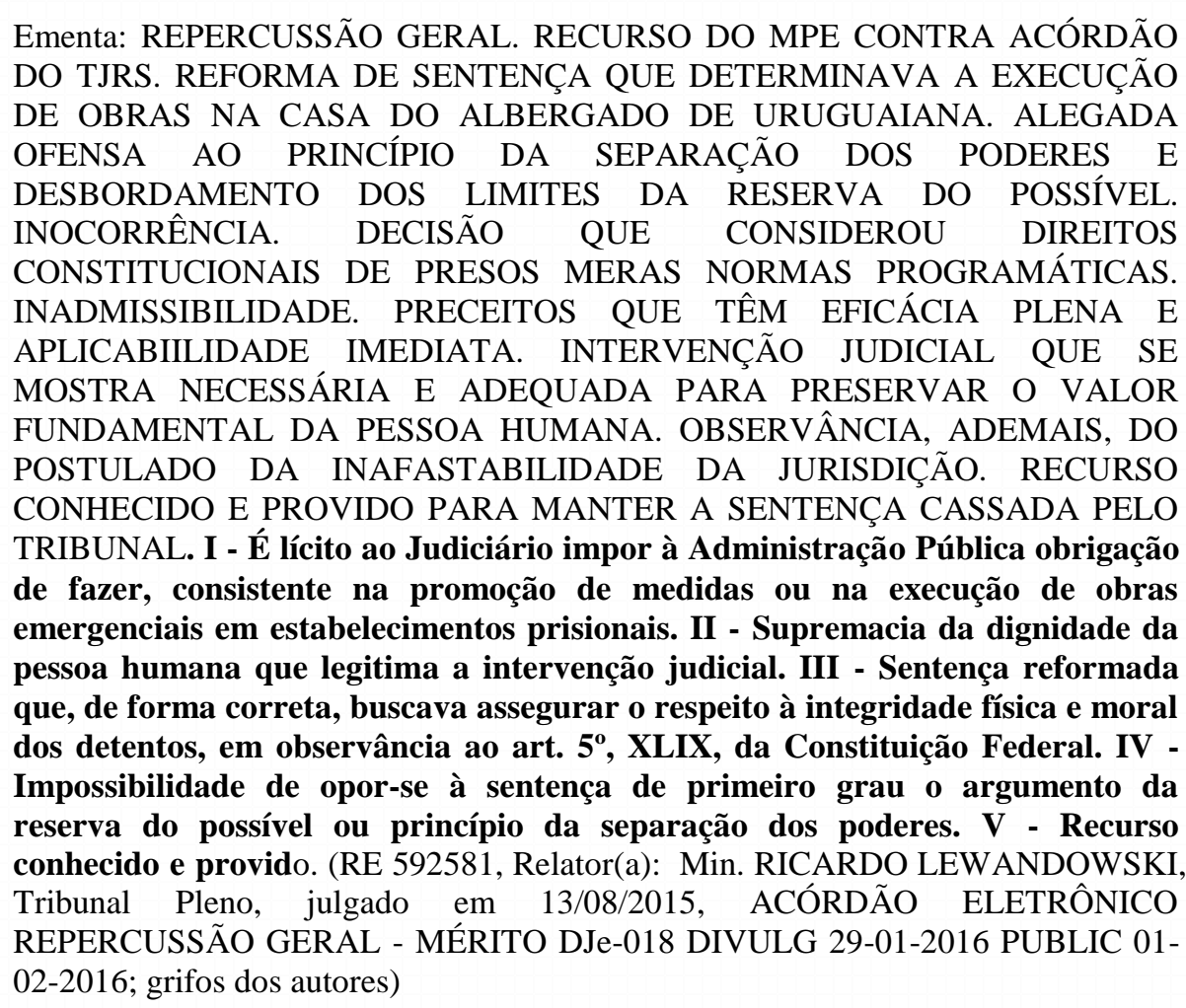

Também recentemente, o Supremo Tribunal Federal no julgamento da Medida Cautelar na ADPF n. 347, ajuizada pelo Partido do Socialismo e Liberdade (PSOL), acolheu em parte os pedidos. Textualmente, assim dispõe a ementa (STF, 2015b)

CUSTODIADO - INTEGRIDADE FÍSICA E MORAL - SISTEMA
PENITENCIÁRIO - ARGUIÇÃO DE DESCUMPRIMENTO DE PRECEITO
FUNDAMENTAL - ADEQUAÇÃO. Cabível é a arguição de descumprimento de
preceito fundamental considerada a situação degradante das penitenciárias no Brasil.

\footnotetext{
${ }^{37}$ Nesse julgado não há referência expressa ao "estado de coisas inconstitucional”, mas revela-se importante porque erigiu o princípio da dignidade humana ao pedestal que lhe é devido, tendo, para tanto, que adentrar no campo da efetivação das políticas públicas e seu respectivo descumprimento por parte dos Poderes competentes.
} 
SISTEMA PENITENCIÁRIO NACIONAL - SUPERLOTAÇÃO CARCERÁRIA CONDIÇÕES DESUMANAS DE CUSTÓDIA - VIOLAÇÃO MASSIVA DE DIREITOS FUNDAMENTAIS - FALHAS ESTRUTURAIS - ESTADO DE COISAS INCONSTITUCIONAL - CONFIGURAÇÃO. Presente quadro de violação massiva e persistente de direitos fundamentais, decorrente de falhas estruturais e falência de políticas públicas e cuja modificação depende de medidas abrangentes de natureza normativa, administrativa e orçamentária, deve o sistema penitenciário nacional ser caraterizado como "estado de coisas inconstitucional". FUNDO PENITENCIÁRIO NACIONAL - VERBAS - CONTINGENCIAMENTO. Ante a situação precária das penitenciárias, o interesse público direciona à liberação das verbas do Fundo Penitenciário Nacional. AUDIÊNCIA DE CUSTÓDIA OBSERVÂNCIA OBRIGATÓRIA. Estão obrigados juízes e tribunais, observados os artigos 9.3 do Pacto dos Direitos Civis e Políticos e 7.5 da Convenção Interamericana de Direitos Humanos, a realizarem, em até noventa dias, audiências de custódia, viabilizando o comparecimento do preso perante a autoridade judiciária no prazo máximo de 24 horas, contado do momento da prisão. (ADPF $347 \mathrm{MC}$, Relator(a): Min. MARCO AURÉLIO, Tribunal Pleno, julgado em 09/09/2015, PROCESSO ELETRÔNICO DJe-031 DIVULG 18-02-2016 PUBLIC 19-02-2016). (grifos dos autores)

Da decisão prolatada se verificam os requisitos estipulados para que se possa aplicar o “estado de coisas inconstitucional" que foi incorporado pelo Supremo Tribunal Federal, a $\operatorname{saber}^{38}$ : i) violação de preceitos fundamentais decorrentes de atos do Poder Público; ii) inexistência de outro meio eficaz de sanar a lesividade; iii) situação retratada decorrente de falhas estruturais em políticas públicas, de modo que a solução do problema dependa da adoção de providências por parte dos diferentes órgãos legislativos, administrativos e judiciais da União Federal, dos Estados e do Distrito Federal; e iv) prolongada omissão das autoridades no cumprimento de suas obrigações para garantia e promoção dos direitos fundamentais ${ }^{39}$.

Além disso, conforme ressalta Pereira e Gonçalves (2015, p. 148)

Na decisão do STF que empregou o conceito, o relator destacou a severidade e persistência das violações a direitos humanos nos presídios brasileiros, afirmou que a responsabilidade seria atribuível aos três poderes do Estado, bem como a todos os entes da federação, já que as transgressões maciças decorrem da falta de coordenação institucional entre os agentes públicos e de falhas estruturais. Nos votos que até agora circularam, porém, não foi dado grande destaque aos argumentos relacionados à necessidade e utilidade de uma solução coletiva, talvez pela circunstância de não haver, a exemplo do que ocorre na Colômbia, a necessidade de superar uma limitação de ordem processual.

Sendo assim, até o presente momento a observação é de que o Supremo Tribunal Federal passou a acolher a teoria da declaração de inconstitucionalidade em decorrência do

\footnotetext{
${ }^{38}$ Medida Cautelar na Argüição de Descumprimento de Preceito Fundamental 347 Distrito Federal. Relatório Ministro Marco Aurélio Mello, p. 3-13. Disponível em: <http://www.stf.jus.br/portal/processo/ verProcessoAndamento.asp?numero $=347 \&$ classe $=\mathrm{ADPF} \&$ origem $=\mathrm{AP} \&$ recurso $=0$ \& tipoJulgamento $=\mathrm{M}>$. Acesso em 15 jun 2016.

39 In casu, a aplicação do "estado de coisas inconstitucional" pelo Supremo Tribunal Federal representa, em maior ou menor medida, o reconhecimento de uma omissão estatal grave que dilacera a proteção dada pela Constituição Federal, mormente, neste caso, no que tange à dignidade humana dos encarcerados.
} 
“estado de coisas inconstitucional”. Abriu-se, com isso, mais um leque de oportunidades para a declaração da inconstitucionalidade por omissão estatal ${ }^{40}$. Conforme Campos discorre (2015, p. 220-228)

Trata-se de graves deficiências e violações de direitos que se fazem presentes em todas as unidades da Federação brasileira e podem ser imputadas à responsabilidade dos três poderes: Legislativo, Executivo e Judiciário. Significa dizer: são problemas tanto de formulação e implementação de políticas públicas quanto de aplicação da lei penal. (...)

Por certo que, não se trata de inércia de uma única autoridade pública, nem de uma única unidade federativa, e sim do funcionamento deficiente do Estado como um todo que tem resultado na violação desses direitos. Os poderes, órgãos e entidades federais e estaduais, em conjunto vem se mantendo incapazes e manifestado falta de vontade política em buscar superar ou reduzir o quadro objetivo de inconstitucionalidade. Falta sensibilidade legislativa quanto ao tema da criminalização das drogas, razão maior das prisões.

O próprio Judiciário tem contribuído com o excesso de prisões provisórias, mostrando falta de critérios adequados para tanto. Falta estrutura de apoio judiciário aos presos. Trata-se, em suma, de mau funcionamento estrutural e histórico do Estado como fator do primeiro pressuposto, o da violação massiva de direitos.

Assim, o que cabe futuramente é fazer-se a reflexão sobre em que medida o Poder Judiciário deve se imiscuir na concretização de políticas públicas, mormente considerando que a sua adoção demanda alocação de recursos orçamentários, atividade esta de função específica do Poder Executivo.

\section{CONCLUSÃO}

Apesar de a Constituição Federal garantir o princípio da dignidade da pessoa humana em várias disposições aos presidiários (art. 1º, III, art. 5, III, XLVII, “e”, XLVIII, XLIX e LVII), não há efetivamente, no cenário brasileiro atual, seu cumprimento adequado, conforme decidido no Recurso Extraordinário n. 592.581. A não observância aos direitos fundamentais que albergam tal princípio, conforme reconhecido pelo Supremo Tribunal Feral quando do julgamento da Medida Cautelar na ADPF nº 347, é grave, sistêmica e constante.

Por essa razão o Supremo Tribunal Federal, apesar de avançar em seara teoricamente reservada aos Poderes Legislativo e Executivo, o fez para sanar sua omissão em malferir a direitos fundamentais, baseando-se no chamado "estado de coisas inconstitucional",

\footnotetext{
${ }^{40}$ Não somente a inércia do legislador pode ser objeto de insurgência, mas também a omissão deflagradora da condição fática de um "estado de coisas inconstitucional", causado pelo Poder Executivo, igualmente pode ser objeto de questionamento, presentes os requisitos autorizadores, principalmente quanto à questão da efetividade de direitos fundamentais.
} 
desenvolvido pela Corte Colombiana e de verificação condicionada a uma situação grave, sistêmica e duradoura.

A decisão no julgamento da Medida Cautelar na ADPF nº 347 reconhece que há evidente inconstitucionalidade por omissão administrativa na manutenção do sistema prisional na situação em que se encontra e que medidas precisam ser adotadas por força de comando constitucional dotado do atributo de imperatividade e efetividade, segundo apregoa o neoconstitucionalismo vigente (dito constitucionalismo de resultado).

Ainda, apesar da atuação do Judiciário em aparente detrimento dos Poderes constituídos e competentes por tais políticas, a decisão resulta em concreto avanço na defesa dos direitos fundamentais dessa minoria e que não conta com o apoio social efetivo, mas que merece ser também tratada com a dignidade.

Torna-se, todavia, necessário que o conceito de "estado de coisas inconstitucional" seja melhor precisado pela doutrina e jurisprudência, de sorte que o seu reconhecimento não implique insegurança e írrita ingerência do Poder Judiciário nas competências dos demais Poderes.

\section{REFERÊNCIAS}

ABRANCHES, Sérgio. Reforma política no Brasil. In: AVRITZER, Leonardo; ANASTASIA, Fátima (Org). Reforma política no Brasil. Belo Horizonte: Ed. UFMG, 2007. 1988, p. 5-33.

. Presidencialismo de coalizão: O dilema institucional brasileiro. Dados, v. 31, n. 1,

ALIGHIERI, Dante. A divina comédia. PINHEIRO, José Pedro Xavier (Trad.). São Paulo : eBooksBrasil, 2003. Disponível em:

http://www.ebooksbrasil.org/adobeebook/divinacomedia.pdf>. Acesso em: 15 jun 2016.

BARCELLOS, Ana Paula de. Violência urbana, condições das prisões e dignidade humana. Revista de Direito Administrativo, v. 254, maio/ago. 2010, p. 39-65.

Neoconstitucionalismo, direitos fundamentais e controle das políticas públicas. Revista Direito Administrativo, v. 240, abr./jun, 2005, p. 83-103.

BARROSO, Luís Roberto. Da falta de efetividade à judicialização excessiva: direito à saúde, fornecimento gratuito de medicamentos e parâmetros para a atuação judicial. 2007. Disponível em: <http://www.conjur.com.br/dl/estudobarroso.pdf> Acesso em: 14.07.2016.

Revista Interesse Público, Belo Horizonte, ano IX, n. 46, nov. 2007,

p. 31-62. 
BOLDT, Raphael. Criminologia midiática: do discurso punitivo à corrosão simbólica do garantismo. Curitiba: Juruá, 2013.

BRASIL. CNJ - Conselho Nacional de Justiça. Departamento de Monitoramento e Fiscalização do Sistema Carcerário e do Sistema de Execução de Medidas Socioeducativas DMF. Novo diagnóstico de pessoas presas no Brasil. 2014, p. 1-17. Disponível em: <http://www.cnj.jus.br/images/imprensa/pessoas_presas_no_brasil_ final.pdf >. Acesso em: 15 jun 2016.

CNMP - Conselho Nacional do Ministério Público. Dados inéditos do CNMP sobre sistema prisional. 2013a. Disponível em: <http://www.cnmp.mp.br/portal/todas-asnoticias/3486-dados-ineditos-do-cnmp-sobre-sistema-prisional>. Acesso em 14 jun 2016.

. A visão do Ministério Público sobre o sistema prisional brasileiro. Brasília : CNMP, 2013b. Disponível em: <http://www.cnmp.mp.br/portal/images/portal2013/noticias/2013/Sistema\%20Prisional_web_final_2.pdf>. Acesso em 14 jun 2016.

A visão do Ministério Público sobre o sistema prisional brasileiro - 2016. 2016a. Disponível em: <http://www.cnmp.mp.br/portal/publicacoes/9948-a-visao-doministerio-publico-sobre-o-sistema-prisional-brasileiro-2016>. Acesso em 14 jun 2016.

A visão do Ministério Público sobre o sistema prisional brasileiro

- 2016. Brasília : CNMP, 2016b. Disponível em:

<http://www.cnmp.mp.br/portal/images/Publicacoes/documentos/2016/Livro_

sistema_prisional_web_7_12_2016.pdf >. Acesso em 14 jun 2016.

STF - Supremo Tribunal Federal. Ementas. 2004. Disponível em: <http://www.sbdp.org.br/arquivos/material/343_204\%20ADPF\%202045.pdf>. Acesso em: 18/07/2016.

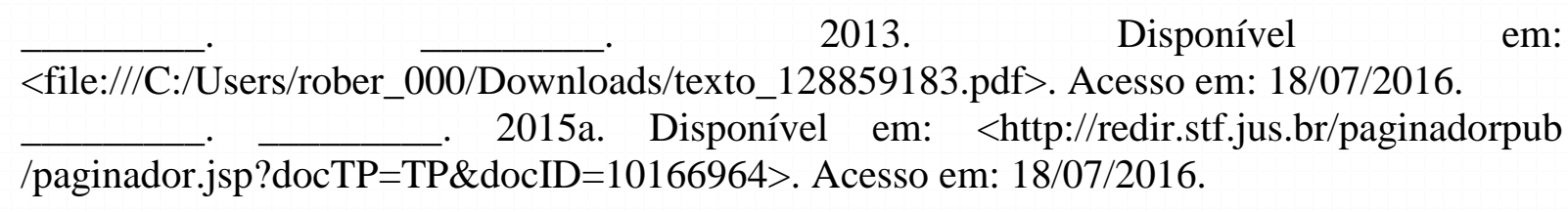
· $2015 \mathrm{~b}$. Disponível em: <http://redir.stf.jus.br/paginadorpub paginador.jsp?docTP=TP\&docID=10300665>. Acesso em: 18/07/2016.

BUCCI. Maria Paula Dallari. O conceito de política pública em direito. In: BUCCI, Maria Paula Dallari (Org.). Políticas públicas: reflexões sobre o conceito jurídico. São Paulo : Saraiva, 2006, p. 1-49.

CAMPOS, Carlos Alexandre de Azevedo. Da inconstitucionalidade por Omissão do "Estado de Coisas Inconstitucional". Tese apresentada, como requisito parcial para obtenção do título de Doutor, ao Programa de Pós-gradução em Direito, da Universidade do Estado do Rio de Janeiro. Área de concentração: Cidadania, Estado e Globalização (Direito Público). Rio de Janeiro, 2015. 
Comisión Interamericana de Derechos Humanos. Informe sobre los derechos humanos de las personas privadas de libertad en las Américas, 2011, pp. 1-247. Disponível em <http://www.oas.org/es/cidh/ppl /docs/pdf/ppl2011esp.pdf>. Acesso em 15 jun 2016.

CORREDOR, Róman J. Duque. Estado de Derecho y justicia: desviaciones y manipulaciones. El Estado de cosas inconstitucional, Provincia Especial, 2006.

DANTAS, Fernanda Priscila Ferreira. A discricionariedade administrativa nas políticas públicas e os direitos sociais. In: Direitos sociais e políticas públicas BIER, Clerilei Aparecida; BADR, Eid; XIMENES, Julia Maurmann (Coord.). Florianópolis: CONPEDI, 2015, p. 45-64. Disponível em <http://www.conpedi.org.br/publicacoes/c178h0tg/rma2ey1m/ w3ndacRYS8qlvLc8.pdf >. Acesso em 15 jun 2016.

FOUCAULT, Michel. Vigiar e punir. Rio de Janeiro : Vozes, 2009.

GÓMEZ SÁNCHEZ, Yolanda. Dignidad y ordenamiento comunitario. Revista de Derecho Constitucional, n. 4, Granada, UGR, jul./set. 2005, p. 219-254.

GRINOVER, Ada Pellegrini; LUCON, Paulo Henrique dos Santos; WATANABE, Kazuo. PL sobre controle jurisdicional de políticas públicas é constitucional. Disponível em: <http://www.conjur.com.br/2015-fev-23/pl-controle-jurisdicional-politica-publicaconstitucional> Acesso em: 18/07/2016.

KANT, Immanuel. Fundamentação da metafísica dos costumes. QUINTELA, Paulo (Trad.). Lisboa: Edições 70, 2008.

LASSALE, Ferdinand. A essência da Constituição. Rio de Janeiro : Lumen Juris, $5^{\text {a }}$ ed., 2000.

MENDES, Gilmar Ferreira. Segurança Pública e Justiça Criminal. 2015. Disponível: <http://www.conjur.com.br/2015-abr-04/observatorio-constuticional-segurancapublica-justica-criminal>. Acesso em: 14.07.2016.

MILLÁN PUELLES, A. Sobre el hombre y la sociedad. Madrid: Rialp, 1976.

MIRANDA, Jorge Manuel Moura Loureiro de. A fiscalização da inconstitucionalidade por Omissão. Revista Direito e Liberdade, v. 14, n. 1, 2012, p. 11-46.

O Globo. Ministro diz que prefere morrer a passar anos em cadeias brasileiras. Nov. 2012. Disponível em: <http://oglobo.globo.com/brasil/ministro-diz-que-prefere-morrer-passar-anosem-cadeias-brasileiras-6718740>. Acesso em 13 ago 2016.

PEREIRA, Jane Reis Gonçalves; GONÇALVES, Gabriel Accioly. Inconstitucionalidade sistêmica e multidimensional: transformações no diagnóstico das violações à Constituição. Revista Juris Poiesis, ano 18, ${ }^{\circ} 18$, jan-dez.2015, p. 130-159.

SARMENTO, Daniel. A ponderação de interesses na Constituição. Rio de Janeiro: Lúmen Júris, 2000. 
SILVA SANCHEZ, Jesús-María. La expansion del derecho penal: aspectos de la política criminal em las sociedades postindustriales. 2. ed., Madrid: Civitas, 2001.

STRECK, Lenio Luiz. O que é preciso para (não) se conseguir um Habeas Corpus no Brasil. 2015. Disponível em: <http://www.conjur.com.br/2015-set-24/senso-incomum-preciso-naoobter-hc-brasil>. Acesso em: 18/07/2016.

VIEIRA JUNIOR, R. J. A. Separação de Poderes, Estado de Coisas Inconstitucional e Compromisso Significativo: novas balizas à atuação do Supremo Tribunal Federal. Texto para Discussão $\mathrm{n}^{\circ}$ 186. Brasília: Núcleo de Estudos e Pesquisas/CONLEG/Senado, Dezembro/2015. 2015. Disponível em: 〈www.senado.leg.br/estudos〉. Acesso em: 12/07/2016>. Acesso em: 18/07/2016. 